\title{
ARTICLE
}

\section{Sludge and transaction costs}

\author{
Sina Shahab ${ }^{1 \star ~(D) ~ a n d ~ L e o n h a r d ~ K . ~ L a d e s ~}{ }^{2}$ (D) \\ ${ }^{1}$ School of Geography and Planning, Cardiff University, Cardiff, UK and ${ }^{2}$ Environmental Policy and Geary \\ Institute for Public Policy, University College Dublin, Belfield, Dublin 4, Ireland \\ ${ }^{\star}$ Correspondence to: School of Geography and Planning, Cardiff University, Glamorgan Building, King \\ Edward VII Avenue, Cardiff CF10 3WA, UK. E-mail: shahabs@cardiff.ac.uk
}

(Received 28 August 2020; revised 19 January 2021; accepted 10 March 2021)

\begin{abstract}
Behavioral scientists have begun to research 'sludge,' excessive frictions that make it harder for people to do what they want to do. Friction is also an important concept in transaction-cost economics. Nevertheless, sludge has been discussed without explicit referral to transaction costs. Several questions arise from this observation. Is the analogy to friction used differently in both literatures? If so, what are the key differences? If not, should we develop the concept of sludge when the well-established literature on transaction costs already exists? This conceptual article shows that sludge and transaction costs are related, but distinct, concepts, and that the literature on sludge can benefit from incorporating elements from transaction-cost research. For example, we suggest defining sludge as aspects of the choice architecture that lead to the experience of costs, organize sludges using a typology inspired by the transaction-cost literature, highlight specificity, uncertainty, and frequency as important determinants of the 'sludginess' of choice architecture, and show that sludge audits can be conducted using methods developed in the transaction-cost literature.
\end{abstract}

Keywords: sludge; transaction costs; behavioral economics; new institutional economics; frictions

\section{Introduction}

Behavioral insights can be used to help people achieve their long-term goals without limiting their freedom of choice. Thaler and Sunstein (2008) call this nudging. But behavioral insights can also be used to make it more difficult for people to achieve their long-term goals. The phrase for this 'dark cousin' of nudging has recently been termed as 'sludge' (Thaler, 2018; Sunstein, 2019b). Early definitions of sludge view it as nudging for evil (Thaler, 2018), ${ }^{1}$ or as excessive or unjustified friction that makes it harder for people to do what they wish (Sunstein, 2020). Sludge impedes

\footnotetext{
${ }^{1}$ We can differentiate sludge from dark nudging. The former makes good decisions more difficult (mainly by increasing friction) and the latter makes bad decisions easier to enact (e.g., by reducing frictions) (Thaler, 2018; Soman et al., 2019; Sunstein, 2020). Sludging can also be related to ethically unacceptable goals (Lades \& Delaney, 2020).

(c) The Author(s), 2021. Published by Cambridge University Press. This is an Open Access article, distributed under the terms of the Creative Commons Attribution licence (https://creativecommons.org/licenses/by/4.0/), which permits unrestricted re-use, distribution, and reproduction in any medium, provided the original work is properly cited.
} 
decision-making by making it more difficult for people to navigate through their everyday lives (Sunstein, 2019a). ${ }^{2}$

Examples of sludge in the private and the public sector include unnecessarily complicated and cumbersome paperwork and form-filling requirements, hidden add-on fees, long and confusing fine print, unfavorable default settings, inconvenient cashback and refund conditions, messages that induce psychological costs in the form of negative emotions, subscription traps, and bureaucratic red tape (Akerlof \& Shiller, 2015; Soman et al., 2019; Sunstein, 2020).

As a result of sludge, take-up of government programs can be low, profits of firms can be high at the expense of consumer welfare, people can become frustrated, stressed, and sometimes humiliated, and exercising some basic human rights can be rendered more difficult (Thaler, 2018; Soman et al., 2019 Sunstein, 2019b). Sludge can influence everybody's decisions, but it is particularly powerful when humans are present-biased, overoptimistic, or show other deviations from rationality identified in the behavioral sciences.

While examples of sludge are abundant in the emerging discussions on the dark side of behavioral science, the conceptional work on sludge is in its nascent stage. ${ }^{3}$ To make progress, we need to define what sludge is and what it is not. We also need to identify different types of sludge and to establish the main factors that determine whether a process is 'sludgy' or not. Having established such details will allow us to conduct more systematic 'sludge audits' (Sunstein, 2020) in which different types of sludge can be identified in private and public institutions. In this article, we suggest advancing the conceptual literature on sludge by integrating the literature on sludge (mainly discussed within behavioral science) with the literature on 'transaction costs' (mainly discussed in the new institutional economics literature).

Transaction costs are typically defined as all costs involved in a transaction, other than the costs of physical production (Webster \& Lai, 2003; Nilsson \& Sundqvist, 2007). ${ }^{4}$ More substantially, transaction costs are the sum of the direct and indirect costs of making economic transactions on a market. They describe all costs that make a transaction happen but that do not create value (Coggan et al., 2015; Shahab et al., 2018a). They include the costs of finding appropriate opportunities for market transactions, for example, exchanging and trading in the market, and the costs of creating and enforcing property rights (Allen, 1999). Williamson (1985) uses the analogy between mechanical frictions and transaction costs. $\mathrm{He}$ argues that if engineers look for frictions in mechanical systems, economists

\footnotetext{
${ }^{2}$ The words 'excessive' and 'unjustified' are relevant in this definition. It suggests that there are many valid reasons for friction, including programme integrity, self-control problems, privacy, security issues, the acquisition of useful data (Sunstein, 2019b), and the creation of decision points (Soman et al., 2010). But these frictions are not sludge under this definition, as they are essential or beneficial and not excessive and harmful. Whether sludge is always and by definition welfare-reducing is subject to a current debate (e.g., Mills, 2020), and we will have something to say about that debate in this article's subsection 'A definition of sludge'.

${ }^{3}$ For example, Sunstein (2020) defines sludge as excessive friction and Sunstein and Gosset (2020) investigate the optimal level of sludge. But if sludge is excessive (by definition), optimal sludge should be zero.

${ }^{4}$ The concept of 'transaction costs' was conceptually introduced by Coase (1937) to explain why firms exist. The concept was then further developed mainly by new institutional economics scholars (Williamson, 1985; Cheung, 1987; North, 1992).
} 
need to take account of transaction costs. Three types of transaction costs are often distinguished: search and information costs, bargaining costs, and policing/enforcement costs. Additionally, transaction costs are often linked to the creation and enforcement of property rights (Dahlman, 1979; Allen, 1999). ${ }^{5}$

Both the literature on sludge and the literature on transaction costs rely on the analogy to friction in mechanical systems. ${ }^{6}$ However, the concept of sludge has been introduced without reference to transaction costs. Several questions arise from this observation: Do transaction cost and sludge theories analyze and explain the effects of friction on economic or policy outcomes in the same way? If yes, is there any need for developing a new concept such as sludge? If no, what are the key differences in their approaches or rationales and how can the sludge literature learn from over 50 years of transaction-cost research? This article aims to answer these questions with the aim of developing the growing conceptual literature on sludge.

We start by bringing together and synthesizing the literature on transaction costs and the literature on sludge with two main objectives: (1) to identify similarities and differences across both areas and (2) to show whether/how the work on sludge can benefit from insights generated in transaction-cost economics. To this end, the next section shows that there is considerable overlap in the concepts and their approaches, but also highlights some key differences. We then describe how the literature on sludge can benefit from insights gained in transaction-cost research, first suggesting to define sludge as aspects of the choice architecture that lead to the experience of costs and discussing this definition. Second, we borrow from transaction-cost typologies to develop a typology of sludge that differentiates between different choice architectures that lead to search costs, evaluation costs, implementation costs, and psychological costs. Third, we discuss the extent to which the main determinants of transaction costs (specificity, uncertainty, and frequency) are also determinants of sludge. Finally, we show how approaches to measuring transaction costs as well as the other insights gained from the transaction-cost literature can inform 'sludge audits.' We conclude the article by suggesting avenues for future research as well as thoughts on sludge reduction in private and public contexts.

\section{Sludge and transaction costs: similarities and differences}

This section compares the concepts of sludge and transaction costs as defined above in the Introduction, highlighting some similarities and differences across both concepts. A complete description of all similarities and difference is beyond the scope of this article. Instead, we hope to provide a useful synthesis to spark some discussion across the two literatures. We focus on similarities and differences with potential for transaction-cost research to inform the discussions of sludge, as described in the

\footnotetext{
${ }^{5}$ It is worth noting that while term 'transaction costs' suggests that it only applies to costs arising from a transaction, it is sometimes used more broadly (Wang, 2003; Buitelaar, 2004) to also include actions, as opposed to 'trans-actions' (Commons, 1931).

${ }^{6}$ Friction, in the mechanical context, is the force resisting the relative motion of surfaces and material elements sliding against each other (Atkins \& Escudier, 2013). Soman (2020) makes the analogy to friction very explicit when he introduces sludge by describing a metaphorical city in which some houses do not receive water from the water grid due to (actual) sludge that leads to blocked pipes.
} 
following section on 'Informing discussions on sludge with insights from transactioncost economics.'

\section{Bounded rationality}

A key similarity across the literatures on transaction costs and sludge is that both literatures share the view that human behavior is not always best described by the rational agents that maximize their utility under constraints as depicted in many economics textbooks. Transaction-cost economists often cite the influence of Herbert Simon's research on satisficing and highlight that people are intendedly rational, but only limitedly so' (Simon, 1997, p. xxiv). They argue that bounded rationality can contribute to increased transaction costs; if people were fully rational, less time and effort would need to be spent to allow transactions to happen. ${ }^{7}$

The behavioral economic literature goes a step further and argues that people are not only boundedly rational, but also that these deviations from rational behavior can be predicted in directional hypotheses (Thaler, 2015). Predictable deviations from rationality are called biases, and behavioral economists have identified many of these biases over the last three decades (including inertia, present bias, optimism bias, overconfidence, biased expectations, loss aversion, and inattention to name just a few) (Dhami, 2016). It is helpful to have this view of human behavior in mind when discussing the origins and consequences of transaction costs and sludge in the next subsections.

\section{Origins: institutions and choice architecture}

The concept of transaction costs originates from the literature on institutions. Institutions are sometimes described as the 'rules of the game' (North, 1990) and can lead to more or less frictions in economically relevant transactions. On the macro level, institutional environments are composed of political, social, and legal ground rules, and these rules can slow down or speed up economic activities depending on their design. On the micro level, institutional arrangements can lead to frictions when cooperation or competition between different economic actors is hindered by, for example, complicated rules (Williamson, 1993).

The term sludge originates from a literature in behavioral science that highlights the importance of the choice architecture as a main determinant of human behavior. Choice architecture describes the contexts in which individuals make decisions (Thaler \& Sunstein, 2008). These contexts can make it easy for people to make welfare-promoting decisions, for example when information is described in simple terms. Thaler and Sunstein (2008) call modifications of the choice architecture that facilitate welfare-promoting choices 'nudging.' But choice architecture can also complicate decisions, for example when the completion of unnecessary forms is required or when prices of consumer products are hidden and communicated without much transparency. In these situations, the choice architecture can be called 'sludgy' as it

\footnotetext{
${ }^{7}$ However, the transaction-cost literature does not view bounded rationality as a sufficient condition for the existence of transaction costs. For example, if all the agents involved in a transaction were fully trustworthy, bounded rationality would not necessarily lead to higher transaction costs (Williamson, 1993).
} 
creates unnecessary frictions that make it more difficult for people to make decisions that increase their welfare.

Nudges that rely on changes of the choice architecture do not restrict people's freedom to make decisions or change incentives significantly. Instead, these changes use psychological levers to make it more likely that one option is chosen over another. The importance of the choice architecture has been overlooked in traditional economic thinking where supposedly minor situational factors have been deemed irrelevant for the behavior of the rational agents in economics textbooks and hence for economic analysis. But findings from behavioral economics and psychology about bounded rationality and predictable biases suggest that these 'supposedly irrelevant factors' do matter a lot (Thaler, 2015).

Institutions and choice architecture are not identical concepts. For example, nobody would deem institutions, such as property rights, marriage, and religion as (supposedly) irrelevant. Moreover, institutions are often designed centrally, and the choice architecture is typically designed by street-level bureaucrats or lower-level workers in organizations. However, the two concepts are related. When institutions are defined as the 'rules of the game,' we can define the choice architecture as the 'design of the game.'

Consider chess as an example. The rules of the game dictate that the board is organized in $8 \times 8$ squares, that the bishop can move diagonally, and that the game is over when the king is taken. Within the limits provided by these rules, the game can happen in loud or quiet environments, different pieces can look differently, and the material of the board and the pieces can vary. While these design aspects might not influence the game of grandmasters, beginners might very well be affected, and some designs can make it harder to follow the rules than other designs.

As such, the design, or the choice architecture, can make it either easier or more difficult to make good decisions. Accordingly, both institutions and choice architecture influence our decisions. But while institutions necessarily influence everybody's decisions, including those decisions of the rational agents from economics textbooks and sometimes limit freedom of choice, changes of the choice architecture (often in the form of changes of supposedly irrelevant factors) have particularly strong effects on boundedly rational individuals and never reduce freedom of choice.

Both institutions and the choice architecture may originate from deliberate decisions. For example, government officials may make it excessively difficult for people to receive welfare benefits and companies may make it difficult to redeem mail-in rebates to gain financial benefits in a somewhat opaque way. Moreover, financial adviser lobbies have an incentive to keep the tax system complicated to guarantee demand for their services. On the other hand, institutions with high transaction costs as well as sludgy choice architecture can also result from unintentional processes where, for example, paperwork requirements accumulate over time, potentially because the designers of the institutions and the choice architects themselves are boundedly rational and not aware of the frictions they create for end users. Public officials and industry representatives might not be able to see these frictions emerging as there might be an 'empathy gap' where experts are blind to problems that nonexperts might encounter (Soman et al., 2019). 


\section{Consequences: effectiveness, efficiency, and equity}

Transaction costs can have many consequences. The transaction-cost literature often distinguishes between consequences related to reduced levels of effectiveness, efficiency, and equity (Rørstad et al., 2007; Kuperan et al., 2008; Jaraite et al., 2010; Coggan et al., 2015; Mack et al., 2019; Shahab \& Viallon, 2019; Shahab et al., 2019b). Transaction costs influence the effectiveness of market transactions when, for example, contracts are too complicated to be set up so that sales are not agreed upon. Thus, fewer transactions happen than it would be optimal. They can influence the effectiveness of government programs when take-up rates of welfare benefits are low due to paperwork burdens. Transaction costs reduce efficiency when, for example, they lead to dead weight losses due to too little trade on a market or when citizens need to spend too much time and effort to receive welfare benefits. High levels of transaction costs in a market mean that a lot of resources are needed to complete transactions. Also, transaction costs can influence how equitable outcomes of market transactions are when they make it easier or less costly for some than for others to make transactions. For example, the transaction costs of the EU Emissions Trading Scheme are lower for participants with larger allocations than for those with smaller allocations. While the average transaction costs for smaller firms are around €2.02 per tonne, larger firms pay only about $€ 0.05$ per tonne (Jaraite et al., 2010).

The sludge literature has also begun to discuss the consequences of sludge and we can organize these consequences according to their effects on effectiveness, efficiency, and equity, as well. In terms of effectiveness in the public sector, sludge can reduce the take-up rates of government programs, reduce acquisitions of permits or licenses (Herd \& Moynihan, 2019), and reduce the ability to enjoy individual rights such as the right to vote and the right for free speech (Sunstein, 2020). In the private sector, sludge can reduce the number of rebates that consumers claim (Bar-Gill, 2012) and generally reduce people's freedom understood as the ability to do what they want to do (Sunstein, 2019a). Moreover, when firms compete to design the most deceiving and sludgy choice architecture (rather than competing over price or quality), lower social welfare can be the result (Akerlof \& Shiller, 2015).

In terms of efficiency, sludge in the public sector can increase the time and money spent to achieve given outcomes, for example, when administrative requirements lead to an increased need for administrative capacity and person-time. In the private sector, sludge can reduce efficiency when goods are purchased for more than the market price.

Finally, sludge can have uneven effects on different people, and inequality can increase when sludges have stronger effects on some segments in the population, such as the poor, the elderly, the sick, or those with young children (Christensen et al., 2020). Those most in need of welfare support might also be those who have most difficulties overcoming sludge to obtain the welfare benefits due to low mental bandwidth and being preoccupied with financial and other worries (Shafir \& Mullainathan, 2013). While also fully rational people are likely to be adversely affected by sludge, behavioral biases make sludge especially harmful and sometimes devastating (Sunstein, 2019b). ${ }^{8}$

\footnotetext{
${ }^{8}$ Madsen et al. (2021) discuss more distributional issues related to the effects of friction as dealt with in the literatures on sludge, administrative burden, red tape, and ordeals.
} 


\section{Measurement: direct and indirect costs}

To quantify transaction costs and the consequences of sludge (also in terms of effectiveness, efficiency, and equity), we need to identify the units in which transaction costs and the consequences of sludge can be measured. The transaction-cost literature quantifies transaction costs by measuring the direct and indirect costs incurred by involved parties to complete transactions (McCann \& Easter, 1999; Falconer \& Saunders, 2002; Fang et al., 2005; Kuperan et al., 2008; Coggan et al., 2015; Shahab et al., 2018a). ${ }^{9}$ The direct costs refer to all direct financial (or monetary) costs involved in the transactions. These costs include, for example, administration fees, brokerage fees, the costs of hiring consultants and intermediaries, the costs of transportation and accommodation, and the costs of conducting surveys. The indirect costs often refer to the costs of time spent on each transaction. To monetize time-related costs, reported time inputs are multiplied by standard hourly rates. $^{10}$

The effects of sludge can also be measured in terms of direct costs (i.e., monetary costs in terms of how much money consumers/citizens lose) and indirect costs (e.g., time-related costs in terms of how much time consumers/citizens lose). ${ }^{11}$ Sunstein (2019b), for example, suggests that about 9.78 billion hours have been lost in the USA in 2015 due to paperwork. Additionally, behavioral scientists highlight hedonic psychological costs (another form of indirect costs) related to sludge (Thunström, 2019). First studies are emerging that quantify these psychological costs of sludge, for example, using face recognition techniques (e.g., Hattke et al., 2020). While greater attention has been devoted to quantifying transaction costs than to the quantification of sludge, only a few transaction-cost scholars have attempted to take account of psychological costs when discussing transaction costs (see Hart \& Moore, 2008; Fehr et al., 2009, 2011; Hart \& Holmstrom, 2010; Bartling et al., 2017).

\section{Types: search, bargaining, and enforcement costs}

The transaction-cost literature has identified several types of transaction costs (Dahlman, 1979; Bruce \& Fabozzi, 1991; McCann \& Easter, 1999; Thompson, 1999; McCann et al., 2005; Shahab et al., 2019a). These typologies have helped transaction-cost researchers over the years to think systematically about transaction costs. The typologies have been instrumental particularly in empirical studies that

\footnotetext{
${ }^{9}$ The magnitude of transaction costs varies widely from as low as $1 \%$ of the payment (Falconer \& Whitby, 1999) to as high as $110 \%$ of the payment (Falconer \& Saunders, 2002) depending on the context, the way transaction costs are measured, and the definition of the baseline payment that defines the $100 \%$.

${ }^{10}$ For example, Shahab et al. (2018a) assessed the standard value of time for Maryland farmers as $\$ 22.80$ per hour. They calculated this rate based on the average net income per farm in 2015 , that is, $\$ 40,797$ (Maryland State Archives, 2017), divided by the average annual hours actually worked per worker in the USA in 2015, that is, $1790 \mathrm{~h}$ (OECD, 2017).

${ }^{11}$ The 'effects of sludge' in this sentence refer to the welfare consequences of changing the choice architecture. Sludges can have economic consequences in form of direct monetary costs just like nudges can make people financially better off. These economic costs can arise although sludges and nudges do not change economic incentives significantly.
} 
aim to identify and measure transaction costs in different economic contexts. The literature on sludge has not yet agreed upon a typology. ${ }^{12}$ Perhaps the most popular typology of transaction costs was suggested by Dahlman (1979). He differentiates between (1) search and information costs, (2) bargaining and decision costs, and (3) policing and enforcement costs. We briefly summarize this typology here because it has inspired our thoughts on a sludge typology that is presented in the subsection 'Toward a typology of sludge.'

Dahlman (1979) suggests that people incur search and information costs when searching and collecting information before carrying out transactions. For example, consumers need to spend time and resources to obtain information about potential purchases (e.g., the quality of products and services and the trustworthiness of transaction partners), and companies need to invest time and resources to identify the prices they can sell their products for on the target market. Bargaining costs become relevant once potential transaction partners have been identified. They arise, for example, when interested parties attempt to assess the desire of other agents to participate in the transaction and to obtain information about their willingness to pay or sell. Such bargaining costs can arise in firm-to-firm transactions but are also relevant for transactions within firms and between firms and consumers. Finally, policing and enforcement costs become relevant when parties have come to an agreement and when this agreement needs to be enforced. The parties need to make sure that everybody sticks to the agreements and complies with formal or informal contracts. These costs can include the monitoring of outcomes and the level of compliance with the agreed terms and conditions, as well as the development of monitoring technologies.

\section{Influencing factors: specificity, uncertainty, and frequency}

What are the factors that influence whether transaction costs and sludge are high or low? While the literature on sludge has not yet identified a systematic answer to this question, the transaction-cost literature describes various factors that influence transaction costs (Coggan et al., 2013; McCann, 2013; Shahab et al., 2018c). The literature has mainly focused on three interrelated factors influencing transaction costs: specificity, uncertainty, and frequency (Williamson, 1985, 1996). Specificity (often referred to as 'asset specificity') is a 'specialised investment that cannot be redeployed to alternative uses or by alternative users without a loss in productive value' (Williamson, 1996, p. 377). Specificity, which has various types, ${ }^{13}$ concerns the degree to which

\footnotetext{
${ }^{12}$ The first sludge typology we could identify is by Soman et al. (2019) who differentiate between process sludge, communication sludge, and emotional exclusion sludge. In the literature on administrative burden, Moynihan et al. (2015) suggest that burden come in the form of three types of costs: learning costs describe the time and effort that needs to be spent to identify public services; compliance costs describe the effort and money that has to be spent to comply with administrative requirements; and psychological costs are related to negative emotions such as stigma, stress, and loss of autonomy that arise when people interact with the government (see also Herd \& Moynihan, 2019).

${ }^{13}$ There are different types of specificity, such as the site of production, physical and dedicated assets, human capacity (Williamson, 1981), brand name (Williamson, 1985), time of production (Malone et al., 1987), and procedural specificity (Zaheer \& Venkatraman, 1995).
} 
resources are specific to particular transactions. Some resources can be used in many domains (e.g., money, general computer hardware, or math skills) and other resources are not easily redeployable to other transactions (e.g., specific software and hardware or tacit knowledge about how an organization works). The more specific resources are, the higher are the transaction costs when these resources need to be employed in another area.

Uncertainty can increase transaction costs when transaction partners have limited and/or asymmetric information about cost structures, prices, and potential profits of the transactions. In such cases, contracts are more difficult, expensive, and risky to establish (Williamson, 1975; Dixit, 1996; Saussier, 2000). Different aspects of uncertainty can be distinguished, for example in terms of volatility and ambiguity (Carson et al., 2006). Volatility concerns uncertain future conditions and ambiguity is about the uncertainty in present and past experiences. Transaction costs arise because of both forms of uncertainty and as a result of the actions that transactors must take to manage these uncertainties.

Finally, frequency is discussed in the transaction-cost literature as an influencing factor of transaction costs. Transaction costs are higher when transactions are infrequent than when they are frequent because agents become more efficient over time through a 'learning by doing' effect (Arrow, 1962). ${ }^{14}$ Frequent transactions reduce marginal transaction costs due to the ability to redeploy the collated information and capitalize on standardized processes and contracts. More frequent transactions of the same good or service also enable transactors to capitalize on economies of scale, and individuals' past experiences with an activity can help them to accomplish their tasks in a more efficient way.

\section{Informing discussions on sludge with insights from transaction-cost economics A definition of sludge}

Viewing sludge through the lens of transaction-cost economics, we suggest the following working definition of sludge: sludge describes aspects of the choice architecture that lead to the experience costs.

The costs in this definition refer to costs that need to be paid to make an action happen, but that might not create any value for the person who bears the costs; just like transaction costs are the costs that make a transaction happen, but do not create value. This definition highlights the connection between the literatures on sludge and transaction costs and clarifies how both terms are related, that is, that sludge can lead to costs, such as transaction costs. We use the word 'lead' intentionally here to highlight that sludge and transaction costs are not the same thing, but that one can lead to the other.

The definition also captures that sludge is concerned with specific costs, namely those arising from aspects of the choice architecture. Other types of costs, such as

\footnotetext{
${ }^{14}$ There are interrelations between the three factors of specificity, uncertainty, and frequency. Frequent transactions can reduce uncertainty over the transaction, while creating trust between parties involved. Likewise, asset specificity might impact the frequency of a transaction (Rørstad et al., 2007); a high degree of asset specificity might lead to low frequency.
} 
brokerage fees/commissions, legal fees, and administrative charges, do not arise due to sludge because they do not directly link to aspects of the choice architecture. Linking sludge to the choice architecture highlights the close connection between sludge and the behavioral science literature, which suggests that human behavior is strongly influenced by the contexts in which we make decisions.

The definition suggests that sludge leads to the experience of costs. Since it is this subjective experience of costs that determines whether sludge is present, it is not sufficient to analyze a particular choice architecture to determine whether sludge is present or not (e.g., by observing whether there is a default, a social norm, or a lot of information presented). Additionally, one must observe how individuals interact with this choice architecture. This is in line with the literature on transaction costs that emphasizes the importance of perceived, rather than objective, transaction costs (Miharia \& Woltier, 2010; Mack et al., 2019) and the behavioral public administration literature that defines administrative burden (a subset of sludge) as the experience of cost (e.g., Herd \& Moynihan, 2019). ${ }^{15}$

The focus on subjective experience highlights that the same sludge can lead to different costs for different people. For example, requiring some additional paperwork to be completed can lead to the subjective experience of high costs for people who are currently preoccupied with financial and other worries and, thus, are low on mental bandwidth (Shafir \& Mullainathan, 2013). Other people, who do not perceive these worries, might not experience the same high costs of filling out the same forms. ${ }^{16}$ Highlighting that sludge leads to experienced costs also suggests that sludge includes aspects of the choice architecture that create psychological costs such as frustration, anxiety, stigma, and humiliation. Note, however, that in many situations the subjective experience of costs will align with objective costs, for example in terms of time, effort, and money spent.

Our definition of sludge also speaks to the debate on whether sludge should be defined normatively (sludge is always 'bad') or non-normatively (sludge can be both 'good' and 'bad') [see Mills (2020) arguing for a non-normative definition of nudge and sludge]. Our definition suggests that sludge always leads to the experience of costs, and costs are always welfare-reducing. However, it might very well be the case that the same sludge also leads to benefits for the individual, for the choice architect, or for society as a whole [e.g., as discussed in the context of self-control problems by Soman et al. (2010) and program integrity by Sunstein and Gosset (2020)]. But whether sludge leads to net benefits or net costs, all aspects considered is irrelevant

\footnotetext{
${ }^{15}$ There are more links between the literature on sludge and the literature on public administration as reviewed by Madsen et al. (2021). Their article compares sludge with three other forms of friction: administrative burden (e.g., Burden et al., 2012), red tape (e.g., Bozeman, 2000; Bozeman, 2012), and ordeals (e.g., Nichols \& Zeckhauser, 1982). It highlights, for example, that administrative burden is defined as a subjective experience (although one can use objective measures of experience to quantify it) and that sludge is described as objective changes in friction. We deviate from this perspective on sludge and suggest that sludge must lead to experienced costs to be defined as sludge. The article by Madsen et al. (2021) additionally discusses distributiveness, the object and the domain of frictions, and intentionality as other dimensions on which sludge can be compared with administrative burden, red tape, and ordeals.

${ }^{16}$ The subjective element of costs experienced by the decision maker in our definition links to the as judged by themselves' criterion that Thaler and Sunstein (2008) use to determine whether nudges are libertarian paternalistic or not.
} 
for our definition of sludge. Observing that a person experiences costs that are due to the choice architecture the person navigates in is enough for us to claim that we have identified sludge, independent of whether the sludge also leads to benefits. As such, we suggest that sludge always leads to costs, but determining whether sludge is welfare-reducing (i.e., unjustified and excessive) or welfare-enhancing requires a broader cost-benefit analysis that also integrates benefits to all involved parties (see also Linos et al., 2020). ${ }^{17}$

\section{Toward a typology of sludge}

The universe of sludging is large and there are many types of sludges (e.g., unnecessary paperwork, difficulties to opt out of newspaper subscriptions, and unnecessary waiting periods). A systematic classification of these types of sludge would be beneficial. For example, it would help to develop scorecards that individuals and institutions can use to identify sludge (Soman et al., 2019). ${ }^{18}$ It would also assist in bridging the gap between theoretical and empirical studies on sludge, particularly regarding sludge audits, and prevent overlooking important types of sludge in these audits. Hence, we suggest a sludge typology in this subsection.

Since our definition of sludge connects sludge to the transaction-cost literature, relying on Dahlman's (1979) typology for transaction costs (described in the subsection 'Types: search, bargaining, and enforcement costs') is a good starting point to develop a sludge typology. However, Dahlman's typology is most suited to describe transaction costs that arise in market transactions, and sludge is also present in other situations, for example within organizations and institutions and when citizens interact with the government. Hence, we modify the typology by using broader terms that can describe most examples of sludge currently discussed in the literature. More precisely, and in line with Dahlman's three types of transaction costs, we differentiate between sludge as aspects of the choice architecture that lead to the experience of (1) search costs, (2) evaluation costs, and (3) implementation costs. ${ }^{19}$ We also add a fourth type of cost to account for the emotional consequences of sludge: (4) the

\footnotetext{
${ }^{17}$ As discussed in Madsen et al. (2021), some subfields in the public administration literature suggest that frictions can be overall welfare-enhancing (e.g., when administration is onerous but also useful to identify whether somebody is eligible for a service). Other subliteratures in that field suggest that frictions are always welfare-reducing (e.g., some definitions of red tape assume that there are no benefits to red tape).

${ }^{18}$ Soman et al. (2019) argue that a given choice architecture can be sludgy for some individuals but not for others. They argue that it can be difficult for choice architects (who are experts in their area) to emphasize with nonexperts who experience sludge with detrimental outcomes. Experts can easily navigate through even complex choice architectures and thus might have difficulties identifying the effect of sludge on nonexperts' behavior. A typology will help overcome this empathy gap.

${ }^{19}$ Sludge is particularly relevant when individuals interact with nonhuman systems such as websites, booking systems, and generally in online environments (Costa \& Halpern, 2019). Since the term bargaining does not capture all these transactions as it implies active participation of both bargaining partners, we use the term evaluation costs to describe costs arising from choice architecture that makes it more difficult for people to evaluate the costs and benefits of an action. Evaluation costs include bargaining costs (or the evaluation of the willingness of the potential transaction partners to pay or sell products), but evaluation costs are not limited to bargaining costs. Similarly, implementation costs, as we use the term, are broader than policing and enforcement costs. They include the implementation of agreements between different parties, but also include the costs of sticking to plans people have made before and when people attempt to behave according to their intentions.
} 
Table 1. A typology of four different types of sludge leading to different experienced costs.

\begin{tabular}{|c|c|c|}
\hline Type of cost & Definition & Examples \\
\hline Search costs & $\begin{array}{l}\text { Aspects of the choice architecture } \\
\text { that lead to the experience of } \\
\text { search costs by making it more } \\
\text { difficult to acquire relevant } \\
\text { information about different } \\
\text { options }\end{array}$ & $\begin{array}{l}\text { Offering too many options; } \\
\text { confusopolies; ordering of } \\
\text { search results by profit } \\
\text { margins rather than price }\end{array}$ \\
\hline Evaluation costs & $\begin{array}{l}\text { Aspects of the choice architecture } \\
\text { that lead to the experience of } \\
\text { evaluation costs by making it } \\
\text { more difficult to evaluate the } \\
\text { advantages and disadvantages of } \\
\text { different options }\end{array}$ & $\begin{array}{l}\text { Hidden add-on costs and drip } \\
\text { pricing; hidden extra fees; } \\
\text { untrue discount claims and } \\
\text { moon pricing; long and } \\
\text { confusing fine print }\end{array}$ \\
\hline $\begin{array}{l}\text { Implementation } \\
\text { costs }\end{array}$ & $\begin{array}{l}\text { Aspects of the choice architecture } \\
\text { that lead to the experience of } \\
\text { implementation costs by making it } \\
\text { more difficult to get what you } \\
\text { want and avoid what you do not } \\
\text { want }\end{array}$ & $\begin{array}{l}\text { Hidden subscriptions; } \\
\text { automatically renewing } \\
\text { subscription; unnecessarily } \\
\text { complex paperwork; difficult } \\
\text { return policies; complicated } \\
\text { tax filing }\end{array}$ \\
\hline $\begin{array}{l}\text { Psychological } \\
\text { costs }\end{array}$ & $\begin{array}{l}\text { Aspects of the choice architecture } \\
\text { that lead to the experience of } \\
\text { psychological costs by creating } \\
\text { negative experiences such as } \\
\text { stress, stigma, disempowerment, } \\
\text { and loss of autonomy }\end{array}$ & $\begin{array}{l}\text { Misleading messages that put } \\
\text { psychological pressure on } \\
\text { buyers to purchase; } \\
\text { misleadingly highlighting the } \\
\text { popularity of a product; false } \\
\text { scarcity messages; pressure } \\
\text { selling }\end{array}$ \\
\hline
\end{tabular}

experience of psychological costs. Below and in Table 1, we explain this typology and use it to organize some of the emerging behavioral science literature on sludge, also from behavioral industrial organization (Bar-Gill, 2012; Akerlof \& Shiller, 2015; Grubb, 2015a; Heidhues \& Köszegi, 2018). We, thus, demonstrate that, while there is overlap between the types, many sludges can indeed be organized into one of these four types.

\section{Search costs}

Sludge can increase search costs when aspects of the choice architecture make it more difficult for people to find the relevant information needed for good decision-making. For example, presenting too much information can decrease the motivation to choose or the satisfaction with the finally chosen option (Scheibehenne et al., 2010; Grubb, 2015b). The order in which information is presented can also increase search costs, for example when initially low prices increase throughout the purchasing process (Gabaix et al., 2006). A product might be listed at a very low price, but additional shipping and handling costs or essential 'extras' can increase this price above that of competitors, a characteristic sometimes referred to as 'shrouded attributes' (Gabaix et al., 2006; Ellison \& Ellison, 2009). Generally, the choice architecture can determine whether prices and other product attributes are immediately visible and salient or hidden from sight, which influences how easy or difficult it is to find the 
relevant information. Moreover, the choice architecture can orient people's attention to one area of the product over another potentially more important dimension (Ubel et al., 2015; Bar-Gill, 2019). In the context of interactions between the government and the citizens, sludge can lead to search costs when Web sites are so complicated that it is difficult for citizens to become aware of their eligibility for welfare benefits, tax reductions, or other government benefits (Herd \& Moynihan, 2019).

\section{Evaluation costs}

Sludge can increase evaluation costs when the choice architecture makes it more difficult to evaluate the advantages and disadvantages of different options. In many cases, this creates deviations of perceived attributes from actual attributes of options. For example, the way firms communicate product features, contract terms, and prices can make consumers overestimate benefits and underestimate prices of products such as credit cards, mobile phone contracts, and mortgages (Bar-Gill, 2012). Moreover, predicting how consumers will use products in the future is inherently difficult, and firms can make use of this by hiding overdraft fees and credit limits in the fine print. For example, mobile phone and credit card contracts are often designed to make the evaluation of their actual prices difficult: salient up-front costs are reduced and the less salient, hidden costs such as overdraft fees, are increased. Shrouded attributes do not only increase search costs as described in the previous subsection; they can also make it more difficult to evaluate the costs and benefits of different options.

\section{Implementation costs}

Sludge can lead to higher implementation costs when the choice architecture makes it more difficult for people to get what they want and avoid what they do not want. For example, after people have evaluated the costs and benefits of receiving a monthly service and decided to cancel the service, they must implement that decision. Sludge can make this implementation very difficult when the cancellation process is made complicated and long (Norwegian Consumer Council, 2021). Similarly, excessive paperwork and form filing requirements can make it more difficult for people to participate in government programs, for example when information needs to be provided multiple times, when one's status needs to be certified, although the government is the certifying institution, when submissions are required to be sent by postal mail rather than digitally, or when people are required to actively renew their participation in welfare programs (Herd \& Moynihan, 2019). As many researchers will know, applying for third-party funding can be easy or difficult depending on the administrative requirements in one's institution, and these differences can be described as implementation costs.

\section{Psychological costs}

The literature on sludge frequently refers to psychological costs (Sunstein, 2020). ${ }^{20}$ For example, Hattke et al. (2020) show in a laboratory experiment that bureaucratic red tape creates negative emotional responses as measured using facial recognition

\footnotetext{
${ }^{20}$ Here (and in other instances), the literature on sludge cites insights from the administrative burden literature which places emphasis on citizen experiences with welfare administration (Herd \& Moynihan, 2019).
} 
technology. Other examples of psychological costs of sludge include the stress in dealing with unnecessary frictions with the underlying worry of the risk of losing important benefits, embarrassment that might arise when people need to apply for welfare benefits, self-image concerns related to the requirement to tell others how miserable one is to get welfare benefits, the stigma of participating in programs, the loss of personal autonomy, and a sense of unfairness and animosity among public servants who administer programs (Herd \& Moynihan, 2019). For choice architects, it can be difficult to anticipate these psychological effects of sludge because the designers of the choice architecture may not have experienced these emotions first-hand. Hence, the empathy gap between the choice architect and the end user is likely the strongest when it comes to psychological costs (Soman et al., 2019).

\section{Factors influencing sludge}

As summarized in the section 'Influencing factors: specificity, uncertainty, and frequency,' the transaction-cost literature suggests that, inter alia, specificity, uncertainty, and frequency influence how low or high transaction costs are. These three factors are also important determinants of whether a choice architecture is sludgy or not. First, a highly specific choice architecture can make a change of setting more costly. For example, people may have developed the skills to navigate through the choice architecture of a specific software in their organization. This skill is of limited use in other organizations where people need to navigate through a different choice architecture that can be complex to navigate in at the start. If that is the case, specificity of the choice architecture can be a form of sludge as it creates, for example, implementation costs related to the move from one organization to another.

Second, when a person experiences costs due to a choice architecture that creates uncertainty, sludge can be present. For example, some firms seem to try to reduce cancellations of their services by warning users of the consequences of unsubscribing without clarifying what these consequences are. Similarly, users willing to cancel subscriptions are sometimes asked multiple times to affirm their choice using different words, which can create uncertainty about one's motivation to cancel (Norwegian Consumer Council, 2021). Uncertainty can also make the choice architecture sludgy when multiple steps are required in administrative or other processes and when individuals are not made aware of these steps at the beginning of the process. People may also experience costs when the timing of a service, such as the arrival of a taxi or the delivery of a postal parcel, is uncertain. These are examples where the choice architecture creates uncertainty in individuals and, thus, makes them experience search, evaluation, implementation, and psychological costs.

Finally, the extent of sludge in a choice architecture can also be influenced by the frequency of navigation in this choice architecture. When people first encounter a new choice architecture, they often experience high costs. However, once people have learned to navigate this choice architecture, it becomes less sludgy for them as they experience less search, evaluation, implementation, and psychological costs over time. A choice architecture can be particularly sludgy when people encounter the choice architecture only infrequently (e.g., once a year for the tax returns). Such infrequent requirements to navigate through a largely unchanging choice 
architecture provide business opportunities for third parties to become experts in these choice architectures by reusing collected information and redeploying resources again and again. This allows them to become helpful guides in choice architectures that appear complex and alien to most people.

\section{Sludge audits}

Arguably, the main reasons to better understand sludge are to be able to identify it, to conjecture about its welfare consequences, and to develop ways to reduce sludge if deemed necessary (Soman et al., 2019; Sunstein, 2019b). To identify sludge as a first step in this process, Sunstein (2020) suggests using 'sludge audits.' He argues that private and public organizations can engage in annual sludge audits to identify where and when sludge exists and whether it needs to be reduced. Periodic lookbacks at existing sludge can be conducted to identify the current stock of unnecessary requirements posed to employees and civil servants as well as customers and citizens. To measure sludge, he differentiates between time-related costs, financial costs, and psychological costs (see also the subsection 'Measurement: direct and indirect costs'). When conducting sludge audits, Sunstein argues, cost-effectiveness and cost-benefit analyses should be considered, ${ }^{21}$ and a mix of quantitative and qualitative approaches should be used to look at sludge on a case-by-case basis (Sunstein, 2020).

The insights from the transaction-cost literature, some of them presented in the previous sections of this article, may provide additional guidance on how to design sludge audits. Transaction-cost economics has developed a large body of literature that addresses questions on how to measure transaction costs in theoretical, empirical, and methodological contributions (McCann \& Easter, 1999; McCann et al., 2005; Jaraite et al., 2010; Coggan et al., 2015; Shahab et al., 2018a). Referring to this literature and the previous insights presented in this article, in what follows, we present five crucial aspects to be considered when conducting sludge audits: (1) breaking up the processes into required actions, (2) choosing the appropriate methods, (3) recruiting the relevant participants, (4) asking the right questions, and (5) communicating the benefits of sludge audits.

\section{Breaking up the processes into required actions}

Most sludge audits will proceed in at least two steps. The first step is to break up more complicated processes into smaller subprocesses. This is essential to keep the audit manageable and to identify the specific interventions that can reduce sludge in certain situations. A potential problem arises in this process as, theoretically, each subprocess could be further divided into more and more sub-subprocesses (Tan et al., 2012; Shahab et al., 2018b). To avoid endless divisions into smaller processes, a basic unit of analysis needs to be identified. In the transaction-cost literature, the basic unit of analysis is the transaction (Williamson, 1998), defined as the transfer of

\footnotetext{
${ }^{21}$ Cost-benefit analyses may often be impossible in the context of the quantification of sludge. Sunstein (2020) suggests that an alternative to the cost-benefit analysis is to make assessments of proportionality, asking whether there are significant costs from the sludge and whether these serve significant purposes.
} 
property rights regarding goods, services, information, knowledge, or ideas (Williamson, 1996). For sludge audits, we suggest using the 'required action' as the basic unit of analysis. The required action would be defined as each step that has to be taken in a decision-making process to achieve one's goal as subjectively defined by the individual. The concept of the required action is somewhat broader than the concept of the 'trans-action,' because sludge can also be present when only a single individual makes a decision and no other people are involved who could be the receiver of a transaction. Practically, sludge auditors can ask relevant interview/survey participants to describe the process of, for example, applying for a visa, filing a tax return, or completing a form by breaking down the process into the different actions required. In the second step, a sludge auditor would then analyze each required action using methods/questions as presented in the next subsections.

\section{Choosing the appropriate method}

The transaction-cost literature uses various approaches to measure transaction costs. For example, McCann et al. (2005) identify five different sources of information for measuring transaction costs: (1) interviews or surveys of people and parties involved in transactions, (2) secondary data from other studies, (3) government reports, (4) financial reports, and (5) proposed budgets. However, the most common way to collect data about the size of transaction costs is to use surveys and/or interviews (see, e.g., Falconer \& Saunders, 2002; Fang et al., 2005; Kuperan et al., 2008; Ofei-Mensah \& Bennett, 2013; Shahab et al., 2018a). The main reason for the use of interviews and surveys is that other methods and data sources are not always available to obtain information regarding both ex-ante and ex-post transaction costs (McCann et al., 2005). As such, the most common methods to conduct sludge audits will likely be interviews and surveys as well. Moreover, to start the sludge audit, it is advisable for auditors to go through the process themselves, if possible, attempting to gain a first-hand experience. To bridge the 'empathy gap' (Soman et al., 2019), auditors can alternatively ask a nonexpert to go through the process. Additional methods, such as face recognition experiments to measure psychological costs (Hattke et al., 2020), are likely to become more common over time.

\section{Recruiting the relevant participants}

If sludge auditors decide to use interviews and/or surveys to collect data regarding each of the required actions, the next step will be to recruit the relevant participants. Some studies in the transaction-cost literature separate this process into three steps (Shahab et al., 2018a): (1) defining the population of interest, (2) deciding on a sample size, and (3) selecting a sampling strategy. The population of interest would be a set of all people who are eligible to be interviewed/surveyed in a sludge audit. To define the population of interest, either inclusion (i.e., everyone who has a specific characteristic) or exclusion (i.e., everyone who does not have the specific characteristic) criteria can be used. It is important to include individuals who do navigate in the respective choice architecture to gain insights into experienced costs from those who experience these costs in real life as well. Deciding on the size of the sample of participants depends on the chosen method. For qunatitative surveys and experiments, power analyses can be helpful. In qualitative interviews, the aim is to reach data 
saturation, which describes the point at which no new additional data or no further insights are generated from data collection (Guest et al., 2006). Finally, regarding the sampling strategy, the auditors can choose between different types of purposive and/ or random sampling strategies, depending on the main objectives of the audit and the chosen method.

\section{Asking the right questions}

The second step in most sludge audits will aim to identify sludge related to each of the required actions. To identify valid topics to discuss and questions to ask, it can be helpful to refer to the definition of sludge, the sludge typology, and the influencing factors that we have described above. For example, a good start is to ask participants to indicate whether they experienced costs in the process of enacting the required action. It is worth noting that these costs can be financial (direct costs) or related to time, effort, or psychological burden (indirect costs). Follow-up questions can then ask whether participants experienced specific types of costs (i.e., search costs, evaluation costs, implementation costs, and psychological costs). For example, questions about what made it difficult for participants to acquire relevant information, to evaluate the advantages and disadvantages of options, and to get what they wanted and avoid what they did not want can be asked. Similarly, sludge auditors can directly ask about negative experiences such as stress, stigma, disempowerment, and loss of autonomy.

Once these different costs have been identified, sludge auditors can ask participants to reflect on the sources of these costs, highlighting supposedly irrelevant factors related to the choice architecture. In particular, sludge auditors can invite participants to reflect on the specificity, uncertainty, and frequency of the choice situation. It may be helpful, for example, to ask participants whether they are able to transfer knowledge from one experience to the next, whether they experience uncertainty and are not sure about the right steps in the process, and whether the process would get less costly each time they repeat it.

\section{Communicating the benefits of sludge audits}

For sludge audits to happen, it is essential to get some buy-in from the relevant actors in industry or policy. To obtain this buy-in, it is important to clearly demonstrate the relevance of thinking about the choice architecture and design aspects, rather than thinking only about institutional rules. It can be helpful to communicate some key insights from the behavioral sciences about predictable decision-making biases and the related importance of context effects to highlight why it is important to also consider the choice architecture. Moreover, potential auditors might be experts in the choice architecture that might benefit from a sludge audit. This can lead to an empathy gap, making it difficult for the experts to 'see sludge' (Soman et al., 2019). Hence, it is important to highlight the subjective nature of sludge; that what is sludge for one person is not sludge for another person. It can also be helpful to stress that sludge can grow through unintentional processes over time to highlight that no single individual might be to blame for the existing sludge. Finally, it might be better to avoid using negative language. Both the words 'sludge' and 'audit' may be perceived as threatening and public officials as well as industry 
representatives may be more willing to engage in 'behavioral process reviews,' 'tests for regulatory load,' or 'transaction-cost measurement' than in 'sludge audits.'

\section{Summary and conclusion}

This conceptual article shows that sludge and transaction costs are related, but distinct, concepts. The two concepts are related because sludge can lead to the experience of costs. The two concepts are distinct because sludge can lead to the experience of various types of costs and not only transaction costs. The article suggests that the behavioral science literature on sludge can benefit from incorporating concepts and methods developed in the new institutional economics literature on transaction costs. First, it suggests defining sludge as aspects of the choice architecture that lead to experienced costs. Second, it presents a new typology of sludge that differentiates between aspects of the choice architecture that lead to the experience of (1) search costs, (2) evaluation costs, (3) implementation costs, and (4) psychological costs. Third, the article shows that specificity, uncertainty, and frequency are factors that influence transaction costs as well as how sludgy a choice architecture is. Finally, building on the discussed contributions, the article presents some pragmatic considerations for conducting sludge audits.

Once sludge audits have been conducted, the next step is to reduce the previously identified sludge where adequate. While 'sludge reduction' is beyond the scope of the article [see Sunstein (2019b) for a discussion on sludge reduction], we do provide an outlook on future work on this topic. First, our definition of sludge suggests that sludge reduction refers to changes in the choice architecture that remove those aspects that create experienced search costs, evaluation costs, implementation costs, and psychological costs. Sludge-reduction policies might well differ depending on the type of sludge. Second, while we have focused on changing the choice architecture in this article, our definition of sludge also allows an alternate avenue of sludge reduction: it is possible to educate people to be aware of sludge in its different facets and to help them navigate through the choice architecture efficiently. Such educational strategies could be considered a specific form of 'boosting' (e.g., Grüne-Yanoff \& Hertwig, 2016). In fact, merely providing a language to describe the hassle related to administrative burdens and other frictions of everyday life might already be enough for self-reflective individuals to experience less costs when navigating through complex choice architecture. Third, sludge is often reduced by private agents when intermediaries (e.g., consultants, lawyers, and the tax preparation industry) take care of our paperwork for us. Finally, when sludge is intentional, governments may also consider mandating sludge reductions and, thus, engage in specific forms of 'budging,' that is, the governments' uses of behavioral economic findings to inform where and how to regulate the private sector (Oliver, 2013).

Acknowledgments. We would like to thank the participants of the UCD Behavioural Science Workshop on Sludge, Ibrahim Sorie Kabba for excellent research assistance, and Paul Adams, Stuart Mills, Margaret Samahita, Robert Huggins, and the anonymous reviewers for valuable comments on an earlier draft of the article.

\section{References}

Akerlof, G. A. and R. J. Shiller (2015), Phishing for phools: The economics of manipulation and deception. Princeton: Princeton University Press. 
Allen, D. W. (1999), 'Transaction costs', in B. Bouckaert, and G. De Geest (eds), Encyclopedia of law and economics, Cheltenham: Edward Elgar, 893-926.

Arrow, K. J. (1962), 'The economic implications of learning by doing', The Review of Economic Studies, 29: $155-73$.

Atkins, T. and M. Escudier (2013), A dictionary of mechanical engineering. Oxford: Oxford University Press.

Bar-Gill, O. (2012), Seduction by contract: Law, economics, and psychology in consumer markets. Oxford: Oxford University Press.

Bar-Gill, O. (2019), 'Smart disclosure: Promise and perils', Behavioural Public Policy, 5(2): 1-14.

Bartling, B., M. Grieder and C. Zehnder (2017), 'Competitive pricing reduces wasteful counterproductive behaviors', Journal of Public Economics, 156: 34-47.

Bozeman, B. (2000), Bureaucracy and red tape. Upper Saddle River, NJ: Prentice Hall.

Bozeman, B. (2012), 'Multidimensional red tape: A theory coda', International Public Management Journal, 15: 245-65.

Bruce, M. C. and F. J. Fabozzi (1991), 'A methodology for measuring transaction costs', Financial Analysts Journal, 47: 27-44.

Buitelaar, E. (2004), 'A transaction-cost analysis of the land development process', Urban Studies, 41(13): 2539-2553.

Burden, B. C., D. T. Canon, K. R. Mayer and D. P. Moynihan (2012), 'The effect of administrative burden on bureaucratic perception of policies: Evidence from election administration', Public Administration Review, 72: 741-51.

Carson, S. J., A. Madhok and T. Wu (2006), 'Uncertainty, opportunism, and governance: The effects of volatility and ambiguity on formal and relational contracting', Academy of Management Journal, 49: 1058-77.

Cheung, S. N. S. (1987), 'Economic organization and transaction costs', in J. Eatwell, M. Milgate, and P. Newman (eds), The New Palgrave: A Dictionary of Economics, London: Palgrave Macmillan, 55-58.

Christensen, J., L. Aarøe, M. Baekgaard, P. Herd and D. P. Moynihan (2020), 'Human capital and administrative burden: The role of cognitive resources in citizen-state interactions', Public Administration Review, 80: 127-36.

Coase, R. H. (1937), 'The nature of the firm', Economica, 4(16): 386-405.

Coggan, A., E. Buitelaar, S. M. Whitten and J. Bennett (2013), 'Intermediaries in environmental offset markets: Actions and incentives', Land Use Policy, 32: 145-54.

Coggan, A., M. Van Grieken, A. Boullier and X. Jardi (2015), 'Private transaction costs of participation in water quality improvement programs for Australia's Great Barrier Reef: Extent, causes and policy implications', Australian Journal of Agricultural and Resource Economics, 59: 499-517.

Commons, J. R. (1931), 'Institutional economics', American Economic Review, 21: 648-57.

Costa, E. and D. Halpern (2019), The behavioural science of online harm and manipulation, and what to do about it. London: The Behavioural Insights Team.

Dahlman, C. J. (1979), 'The problem of externality', The Journal of Law and Economics, 22: 141-62.

Dhami, S. (2016), The foundations of behavioral economic analysis. Oxford: Oxford University Press.

Dixit, A. K. (1996), The making of economic policy: A transaction-cost politics perspective. Cambridge, MA: MIT Press.

Ellison, G. and S. F. Ellison (2009), 'Search, obfuscation, and price elasticities on the internet', Econometrica, 77: 427-52.

Falconer, K. and C. Saunders (2002), 'Transaction costs for SSSIs and policy design', Land Use Policy, 19: $157-66$.

Falconer, K. and M. Whitby (1999), 'The invisible costs of scheme implementation and administration', in G. Van Huylenbroeck and M. Whitby (eds), Countryside Stewardship: Farmers, Policies and Markets, Amsterdam: Elsevier.

Fang, F., K. W. Easter and P. L. Brezonik (2005), 'Point-nonpoint source water quality trading: A case study in the Minnesota River basin', JAWRA Journal of the American Water Resources Association, 41: 645-57.

Fehr, E., O. Hart and C. Zehnder (2009), 'Contracts, reference points, and competition-behavioral effects of the fundamental transformation', Journal of the European Economic Association, 7: 561-572.

Fehr, E., O. Hart and C. Zehnder (2011), 'Contracts as reference points-experimental evidence', American Economic Review, 101: 493-525. 
Gabaix, X., D. Laibson, G. Moloche and S. Weinberg (2006), 'Costly information acquisition: Experimental analysis of a boundedly rational model', American Economic Review, 96: 1043-68.

Grubb, M. D. (2015a), 'Behavioral consumers in industrial organization: An overview', Review of Industrial Organization, 47: 247-58.

Grubb, M. D. (2015b), 'Failing to choose the best price: Theory', Evidence and Policy: Review of Industrial Organization, 47: 303-40.

Grüne-Yanoff, T. and R. Hertwig (2016), 'Nudge versus boost: How coherent are policy and theory?', Minds and Machines, 26: 149-83.

Guest, G., A. Bunce and L. Johnson (2006), 'How many interviews are enough?', Field Methods, 18: 59-82.

Hart, O. and B. Holmstrom (2010), 'A theory of firm scope', The Quarterly Journal of Economics, 125: 483513.

Hart, O. and J. Moore (2008), 'Contracts as reference points', The Quarterly Journal of Economics, 123: 148.

Hattke, F., D. Hensel and J. Kalucza (2020), 'Emotional responses to bureaucratic red tape', Public Administration Review, 80: 53-63.

Heidhues, P. and B. Kőszegi (2018), 'Behavioral industrial organization', in B. D. Bernheim, S. Dellavigna, and D. Laibson (eds), Handbook of behavioral economics: Applications and foundations 1. Amsterdam: North-Holland, 517-612.

Herd, P. and D. P. Moynihan (2019), Administrative burden: Policymaking by other means. New York: Russell Sage Foundation.

Jaraite, J., F. Convery and C. Di Maria (2010), 'Transaction costs for firms in the EU ETS: Lessons from Ireland', Climate Policy, 10: 190-215.

Kuperan, K., N. M. R. Abdullah, R. S. Pomeroy, E. L. Genio and A. M. Salamanca (2008), 'Measuring transaction costs of fisheries co-management', Coastal Management, 36: 225-40.

Lades, L. K. and L. Delaney (2020), 'Nudge FORGOOD', Behavioural Public Policy, 1-20.

Linos, E., L. T. Quan and E. Kirkman (2020), 'Nudging early reduces administrative burden: Three field experiments to improve code enforcement', Journal of Policy Analysis and Management, 39: $243-65$.

Mack, G., A. Kohler, K. Heitkämper and N. El-Benni (2019), 'Determinants of the perceived administrative transaction costs caused by the uptake of an agri-environmental program', Journal of Environmental Planning and Management, 62: 1802-19.

Madsen, J. K., K. S. Mikkelsen and D. P. Moynihan (2021), 'Burdens, sludge, ordeals, red tape, oh my!: A user's guide to the study of frictions', Public Administration, http://dx.doi.org/10.1111/padm.12717.

Malone, T. W., J. Yates and R. I. Benjamin (1987), 'Electronic markets and electronic hierarchies', Communications of the ACM, 30: 484-97.

Maryland State Archives (2017), Maryland manual on-line. Annapolis, MD. https://msa.maryland.gov/ $\mathrm{msa} / \mathrm{mdmanual} / \mathrm{html} / \mathrm{mmtoc}$.html (accessed on April 29, 2017).

McCann, L. (2013), 'Transaction costs and environmental policy design', Ecological Economics, 88: 253-62.

McCann, L. and K. W. Easter (1999), 'Transaction costs of policies to reduce agricultural phosphorous pollution in the Minnesota River', Land Economics, 75: 402-14.

McCann, L., B. Colby, K. W. Easter, A. Kasterine and K. V. Kuperan (2005), 'Transaction cost measurement for evaluating environmental policies', Ecological Economics, 52: 527-42.

Miharia, M. and J. Woltier (2010), 'Interlocal government collaboration and perceived transaction costs in Indonesian metropolitan transport planning', International Development Planning Review, 32: 167-89.

Mills, S. (2020), 'Nudge/sludge symmetry: on the relationship between nudge and sludge and the resulting ontological, normative and transparency implications', Behavioural Public Policy, 1-24.

Moynihan, D., P. Herd and H. Harvey (2015), 'Administrative burden: learning, psychological, and compliance costs in citizen-state interactions', Journal of Public Administration Research and Theory, 25: 4369.

Nichols, A. L. and R. J. Zeckhauser (1982), 'Targeting transfers through restrictions on recipients', The American Economic Review, 72: 372-77.

Nilsson, M. and T. Sundqvist (2007), 'Using the market at a cost: How the introduction of green certificates in Sweden led to market inefficiencies', Utilities Policy, 15: 49-59.

North, D. C. (1990), Institutions, institutional change and economic performance. Cambridge: Cambridge University Press. 
North, D. C. (1992), Transaction costs, institutions, and economic performance. San Francisco, CA: ICS Press.

Norwegian Consumer Council (2021), You can log out, but you can never leave: How Amazon manipulates consumers to keep them subscribed to Amazon Prime. Retrieved from: https://www.forbrukerradet.no/ news-in-english/amazon-manipulates-customers-to-stay-subscribed (accessed on January 14, 2021).

OECD (2017), Labour force statistics: Average annual hours actually worked per worker. 29/04/2017 ed. https://stats.oecd.org/Index.aspx?DataSetCode=ANHRS

Ofei-Mensah, A. and J. Bennett (2013), 'Transaction costs of alternative greenhouse gas policies in the Australian transport energy sector', Ecological Economics, 88: 214-21.

Oliver, A. (2013), 'From nudging to budging: Using behavioural economics to inform public sector policy', Journal of Social Policy, 42: 685-700.

Rørstad, P. K., A. Vatn and V. Kvakkestad (2007), 'Why do transaction costs of agricultural policies vary?', Agricultural Economics, 36: 1-11.

Saussier, S. (2000), 'Transaction costs and contractual incompleteness: The case of Électricité de France', Journal of Economic Behavior \& Organization, 42: 189-206.

Scheibehenne, B., R. Greifeneder and P. M. Todd (2010), 'Can there ever be too many options? A meta-analytic review of choice overload', Journal of Consumer Research, 37: 409-25.

Shafir, E. and S. Mullainathan (2013), Scarcity: Why having too little means so much. New York: Henry Holt and Company.

Shahab, S. and F.-X. Viallon (2019), 'A transaction-cost analysis of Swiss land improvement syndicates', Town Planning Review, 90: 545-65.

Shahab, S., J. P. Clinch and E. O'Neill (2018a), 'Estimates of transaction costs in transfer of development rights programs', Journal of the American Planning Association, 84: 61-75.

Shahab, S., J. P. Clinch and E. O'Neill (2018b), 'Timing and distributional aspects of transaction costs in Transferable Development Rights programmes', Habitat International, 75: 131-38.

Shahab, S., J. P. Clinch and E. O'Neill (2018c), 'Accounting for transaction costs in planning policy evaluation', Land Use Policy, 70: 263-72.

Shahab, S., J. P. Clinch and E. O'Neill (2019a), 'An analysis of the factors influencing transaction costs in Transferable Development Rights programmes', Ecological Economics, 156: 409-19.

Shahab, S., J. P. Clinch and E. O'Neill (2019b), 'Impact-based planning evaluation: Advancing normative criteria for policy analysis', Environment and Planning B: Urban Analytics and City Science, 46: 534-50.

Simon, H. A. (1997), Administrative behavior: A study of decision-making processes in administrative organisations. New York: Macmillan.

Soman, D. (2020), Sludge: A very short introduction. Research Report Series Behaviourally Informed Organizations Partnership. Toronto: University of Toronto.

Soman, D., J. Xu and A. Cheema (2010), Decision points: A theory emerges. Rotman Magazine, 64-8.

Soman, D., D. Cowen, N. Kannan and B. Feng (2019), Seeing sludge: Towards a dashboard to help organizations recognize impedance to end-user decisions and action. Research Report Series Behaviourally Informed Organizations Partnership. Rotman: Behavioural Economics in Action.

Sunstein, C. R. (2019a), On freedom. Princeton: Princeton University Press.

Sunstein, C. R. (2019b), 'Sludge and ordeals', Duke Law Journal, 68: 1843-84.

Sunstein, C. R. (2020), 'Sludge audits', Behavioural Public Policy, 1-20. https://papers.ssrn.com/sol3/papers. cfm?abstract_id $=3642942$.

Sunstein, C. R. and J. L. Gosset (2020), 'Optimal sludge? The price of program integrity', Duke Law Journal Online.

Tan, R., V. Beckmann, F. Qu and C. Wu (2012), 'Governing farmland conversion for urban development from the perspective of transaction cost economics', Urban Studies, 49: 2265-83.

Thaler, R. H. (2015), Misbehaving: The making of behavioral economics. New York: W. W. Norton \& Company.

Thaler, R. H. (2018), 'Nudge, not sludge', Science, 361: 431.

Thaler, R. H. and C. R. Sunstein (2008), Nudge: Improving decisions about health, wealth, and happiness. New Haven: Yale University Press.

Thompson, D. B. (1999), 'Beyond benefit-cost analysis: Institutional transaction costs and regulation of water quality', Natural Resources Journal, 39: 517-41. 
Thunström, L. (2019), 'Welfare effects of nudges: The emotional tax of calorie menu labeling', Judgment and Decision Making, 14: 11-25.

Ubel, P. A., D. A. Comerford and E. Johnson (2015), 'Healthcare.gov 3.0 - Behavioral economics and insurance exchanges', The New England Journal of Medicine, 372: 695-8.

Wang, N. (2003), Measuring Transaction Costs: An Incomplete Survey. Ronald Coase Institute, 2.

Webster, C. J. and L. W.-C. Lai (2003), Property rights, planning and markets: Managing spontaneous cities. Cheltenham and Northampton: Edward Edgar.

Williamson, O. E. (1975), Markets and hierarchies, analysis and antitrust implications: A study in the economics of internal organization. New York: The Free Press.

Williamson, O. E. (1981), 'The economics of organization: The transaction cost approach', American Journal of Sociology, 87(3): 548-577.

Williamson, O. E. (1985), The economic institutions of capitalism. New York: Free Press.

Williamson, O. E. (1993), 'Calculativeness, trust, and economic organization', The Journal of Law \& Economics, 36: 453-86.

Williamson, O. E. (1996), The mechanisms of governance. Oxford: Oxford University Press.

Williamson, O. E. (1998), 'Transaction cost economics: How it works; where it is headed', De Economist, 146: $23-58$.

Zaheer, A. \& Venkatraman, N. (1995), 'Relational governance as an interorganizational strategy: An empirical test of the role of trust in economic exchange', Strategic Management Journal, 16: 373-92.

Cite this article: Shahab S, Lades LK (2021). Sludge and transaction costs. Behavioural Public Policy 1-22. https://doi.org/10.1017/bpp.2021.12 